Síntese - Rev. de Filosofia

v. 39 N. 124 (2012): 279-290

\title{
BENTO XVI E O ILUMINISMO
}

\section{(Benedict XVI and the Enlightenment)}

\author{
Juvenal Savian Filho*
}

Resumo: Trata-se, neste artigo, de investigar a análise filosófica do Iluminismo feita por Bento XVI. Para tanto, tomar-se-ão como base textos redigidos não apenas em seu pontificado, mas também no período de seu magistério anterior. Põe-se em destaque a estratégia argumentativa do pontífice ao criticar a pretensa autolimitação da razão imposta por ela mesma em algumas formas hegemônicas do pensamento contemporâneo. A partir daí, extraem-se conclusões em duas frentes: as interpelações que a tradição cristã pode fazer à herança iluminista e, na contrapartida, as interpelações que a herança iluminista também pode fazer aos continuadores do anúncio cristão.

Palavras-chave: Iluminismo, Bento XVI, valor da razão, autolimitação da razão.

Abstract: This paper aims to investigate Benedict XVI's philosophical analysis of the Enlightenment. To do so, some texts written during his pontificate and previous academic teaching will serve as a basis. The emphasis is laid on the argumentative strategy employed by the pope to criticize the self-imposed limitation of reason observed in hegemonic forms of contemporary thought. A two-fold conclusion can be drawn from there: what interpellations can the Christian tradition make to the enlightenment heritage and, inversely, what interpellations can the enlightenment heritage make to the followers of the Christian faith.

Keyowrds: Enlightenment, Benedict XVI, value of reason, self-imposed limitation of reason.

\footnotetext{
* Professor da graduação e pós-graduação em filosofia da Universidade Federal de São Paulo, Campus Guarulhos. Artigo submetido a avaliação no dia 04.10.2011 e aprovado para publicação no dia 24.11.2011.
} 
$\mathrm{P}$ ara os que se aproximam do pensamento de Bento XVI, logo se evidenciam suas inúmeras referências ao Iluminismo. Um caso típi co, sem dúvida, é o discurso por ele pronunciado aos representantes das ciências reunidos na Universidade de Ratisbona, em 12 de setembro de 2006. ${ }^{1}$ Mas, se examinarmos os textos por ele publicados ao longo de seu magistério, veremos menções tanto ou mais explícitas a esse movimento filosófico, como é o caso, por exemplo, dos artigos reunidos em seu livro Os princípios da teologia católica - Esquema e materiais. ${ }^{2}$

No presente estudo, visamos elucidar, em linhas gerais, a abordagem do Iluminismo feita por Bento XVI. Pretendemos fazê-lo em dois momentos: 1) um estudo da análise feita por Bento XVI do Iluminismo em contraponto com dados vindos da tradição cristã; 2) um estudo da análise feita por Bento XVI da tradição cristã em contraponto com o Iluminismo.

\section{Definição de "Iluminismo"}

Na historiografia ocidental, convencionou-se chamar de "Iluminismo" ao período situado entre fins do século XVII e inícios do século XVIII, com término no resultado final das Guerras Napoleônicas (1804-1815). Também conhecido como "Século das Luzes", esse período foi caracterizado por uma série de tradições, advindas da filosofia, da religião, do direito e das mais variadas áreas do saber, unidas a partir do núcleo de um ideário comum. Esse núcleo era constituído pela crença no progresso e na perfectibilidade humana, além da afirmação do conhecimento racional como via de superação dos paradigmas metafísicos.

Na linha de Immanuel Kant, o Iluminismo (Aufklärung) é libertador do ser humano; torna-o livre pelo uso da razão, liberando-o daquilo que Kant denominou de "tutela". Implica, portanto, a afirmação da possibilidade de um mundo melhor, resultante não mais da ação da graça divina ou de algo que a valha, mas pela capacidade racional de desenvolvimento das faculdades humanas. Como consequência direta, o Iluminismo insistia no engajamento político que objetivava a melhoria da vida, e não é exagerado dizer que esse movimento influenciou o destino da humanidade, sobretudo pela elaboração da noção de Estado-nação. ${ }^{3}$

\footnotetext{
${ }^{1}$ Cf. Fé, razão e universidade: recordações e reflexões - Discurso do papa aos representantes das ciências. Universidade de Ratisbona, 12 de setembro de 2006 (texto encontrado em www.vatican.va).

${ }^{2}$ Cf. a tradução francesa: RATZINGER, J. Les principes de la théologie catholique - Esquisse et matériaux. Trad. de Dom J. Maltier. Paris: Téqui, 1982.

${ }^{3}$ Cf. BARRETO, V. P. \& CULLETON, A. Dicionário de filosofia política. São Leopoldo: Unisinos, 2010, p. 271-273.
} 
É perfeitamente emblemático desse movimento o texto de Kant intitulado Resposta à pergunta: Que é Esclarecimento (Aufklärung)?, de 1783. Já na abertura, diz Kant:

Esclarecimento é a saída do homem de sua menoridade, da qual ele próprio é culpado. A menoridade é a incapacidade de fazer uso de seu entendimento sem a direção de outro indivíduo. O homem é o próprio culpado dessa menoridade se a causa dela não se encontra na falta de entendimento, mas na falta de decisão e coragem de servir-se de si mesmo sem a direção de outrem. Sapere aude! Tem coragem de fazer uso de teu próprio entendimento, tal é o lema do esclarecimento. ${ }^{4}$

No texto kantiano, o termo "esclarecimento" (Aufklärung) designa uma atividade humana, a atividade do conhecimento e pensamento livres. É nesse sentido que esse texto é emblemático do movimento que levou o mesmo nome ou correlatos dele na Europa: Aufklärung, na Alemanha; Enlightenment, na Inglaterra; Illuminismo, na Itália; Siècle des Lumières, na França; Ilustración, na Espanha.

Kant insiste que, para obter esse esclarecimento ou essa iluminação nada mais se exige do que a liberdade, e a mais inofensiva das formas de liberdade, qual seja, a de fazer um uso público da razão individual em todas as questões. No entanto, dizia Kant,

Ouço, agora, porém, exclamar de todos os lados: não raciocineis! O oficial diz: não raciocineis, mas exercitai-vos! O financista exclama: não raciocineis, mas pagai! O sacerdote proclama: não raciocineis, mas crede! ${ }^{5}$

Essas personagens, certamente caricaturadas aqui, encarnavam aquilo que o Iluminismo pretendia combater, ou seja, a atitude de não reflexão livre, mas uma reflexão tutelada, exercida sob o mando de uma autoridade. Assim, sob tutela, o indivíduo não exerceria sua capacidade mais específica, que é o uso livre da razão; ele apenas aceitaria aquilo que já havia sido pensado por outros.

Historicamente, essas caricaturas reforçaram a desconfiança que o pensamento moderno e contemporâneo desenvolveu com relação a toda forma de pensamento exercido em continuidade com alguma instituição ou autoridade, como, por exemplo, o poder político ou o magistério eclesiástico. Chegou-se a defender, por exemplo, a anarquia em termos políticos, ou a fé subjetiva, em termos religiosos. Quem nunca ouviu falar da obsolescência da democracia? Ou do velho ditado: "Jesus sim, mas Igreja não"? O apelo à liberdade (que não deixa de ser um valor sem dúvida alguma inegociável)

\footnotetext{
${ }^{4}$ KANT, I. "Resposta à pergunta: Que é Esclarecimento (Aufklärung)?”. In: Textos seletos. Trad. de Raimundo Vier e Floriano de Sousa Fernandes. Petrópolis: Vozes, 2005, p. 63-64.

${ }^{5}$ Idem, p. 65.
} 
e os limites que os costumes humanos revelam com o passar do tempo (o que é natural, dado que estão inseridos na história) levam a desconfiar das instituições, da autoridade e das tradições.

Chega-se, em outras palavras, a um questionamento dos fundamentos dos costumes. Se o ser humano é livre, ele tem o direito e o dever para com ele mesmo de analisar as raízes de tudo aquilo que se lhe apresenta. Essa é, sem dúvida, uma das heranças do Iluminismo.

Ocorre que, em termos filosóficos, e, mais especificamente, gnosiológicos, essa insistência iluminista na necessidade de tudo avaliar crítica e autonomamente levou, na contemporaneidade, a formas de pensamento que defendem uma autolimitação da razão. Isso quer dizer que a razão humana - essa capacidade de perscrutar o funcionamento da Natureza, descobrindo um sentido imanente a ela e exprimindo-o pela linguagem - restringiu o seu campo de investigação ao terreno do que é observável, excluindo da possibilidade de investigação científica tudo aquilo que não se submete ao controle da experiência. Assim, em nome da autonomia da razão, relega-se para o campo do irracional tudo o que não pode ser verificado em termos empíricos. A própria razão, portanto, definiria racionalmente seus limites e as fronteiras do irracional.

É justamente diante dessa tendência contemporânea que podemos evocar a posição de Bento XVI com relação ao Iluminismo e à compreensão deste com base em elementos vindos da tradição cristã.

\section{O Iluminismo em contraponto com a tradição cristã segundo Bento XVI}

Em seu nada ingênuo discurso de 2006, aos representantes das ciências, na Universidade de Ratisbona, Bento XVI agradece pelas grandiosas possibilidades que o desenvolvimento moderno do espírito iluminista ou esclarecido (Aufklärung) abriu ao ser humano. Além disso, em sua conferência de 2000, na Universidade de Paris I, Sorbonne, ${ }^{6}$ discutindo com autores que

${ }^{6}$ Cf. Conferência na Sorbonne, a 27 de novembro de 1999, intitulada "Vérité du christianisme?" (Colloque 2000 ans après quoi?). Há uma tradução brasileira: “Cristianismo. A vitória da inteligência sobre o mundo das religiões". In: Revista 30 Dias. Ano 2000, n.1, p. 33-44. Servimonos, aqui, da edição francesa "Le christianisme - La vraie religion?", que consta como parte II (p. 171-195) do capítulo 4, intitulado "Vérité du christianisme?", publicado em RATZINGER, J. Foi, vérité, tolérance - Le christianisme et la rencontre des religions. Trad. de Maria Linnig e Joachim Bouflet. Paris: Parole et Silence, 2005, p. 145-224. Esse livro foi traduzido e publicado no Brasil (Fé, verdade e tolerância. Trad. de Sivar Hoeppner Ferreira. São Paulo: Instituto Raimundo Lúlio, 2007), mas preferimos utilizar a versão francesa, pois, infelizmente, há problemas técnicos na tradução brasileira. 
defendem uma autolimitação da razão (entre outros, nominalmente, Karl Popper) - e, portanto, correndo o risco de ceder à tentação de defender uma razão heterônoma, obediente a uma verdade exterior (radicalmente antimoderna) -, o então cardeal defende a autonomia da mesma, e denuncia o que, no seu dizer, seria a contradição das racionalidades contemporâneas: para afirmar uma autolimitação da razão, constroem-se modelos hermenêuticos em que não se fala do irracional senão a partir das medidas da razão, ou seja, racionalmente (resolvendo problemas, elaborando métodos etc.), o que termina por restabelecer, na prática, o primado da razão contestado por ela mesma.

Como se pode prever, a crítica de Bento XVI à pretensa autolimitação contemporânea da razão servir-lhe-á para defender a autonomia da mesma razão. Isso se pode ilustrar por sua insistência nos impasses criados pela doutrina evolucionista, não propriamente quando ela se comporta como "teoria científica", mas quando ela pretende apresentar-se como uma teoria universal de todo o real. Para identificar-se o impasse fundamental, bastaria considerar essa hipótese, ou seja, a de o evolucionismo poder constituir-se numa teoria de todo o real. Se a resposta a essa possibilidade for afirmativa, então toda questão sobre a origem e a natureza das coisas, ou mesmo a questão de Deus, não serão mais lícitas nem necessárias, pois, além de serem "pré-críticas", elas serão também irrelevantes para as racionalidades contemporâneas. Com isso, ter-se-á provado, ao mesmo tempo, a autolimitação da razão, pois ela terá delimitado seu território de investigação, que chegaria até os fundamentos do real, obtidos cientificamente, relegando todo outro tipo de pesquisa (sobre a natureza das coisas, por exemplo, ou a questão de Deus etc.) para além das fronteiras do racional; em outros termos, ao irracional, zona nebulosa onde não poderia operar a razão, embora ela possa suspeitar de sua existência. Se, porém, a resposta for negativa, ter-se-á como garantido que é falsa a pretensa autolimitação da razão, o que permitirá dizer que ela pode continuar sua investigação para além dos limites estabelecidos, embora certamente não em termos "científicos" ou tecnicistas, mas em termos filosóficos, teológicos etc.

A estratégia, portanto, do então cardeal Ratzinger consistirá em tentar inviabilizar a resposta afirmativa, e, para tanto, ele sonda a possibilidade de que haja uma forma de superar o campo da pura pesquisa científiconatural, pois, se essa possibilidade efetivar-se, constatar-se-á que as racionalidades contemporâneas, aí incluído o evolucionismo positivista, desprezando-a, não podem pretender-se como um discurso completo sobre o real. Ele analisa, assim, a tese segundo a qual a vida, tal como nós a conhecemos, consiste de "corpos" físicos, ou melhor, de processos e estruturas que "resolvem problemas", de modo que as diversas espécies, por seleção natural, teriam simplesmente "aprendido", isto é, teriam "aprendido" o dinamismo da vida, por um método de "reprodução mais variação", que se incorpora pelo seu próprio exercício, numa regressão infinita. No 
dizer de Ratzinger, uma afirmação desse gênero seria absurda, pois, pretendendo responder, "cientificamente", ao problema de conhecer o dinamismo mais profundo da vida, ela significa, já de saída, a superação do campo da pura pesquisa científico-natural; remete, afinal, ao campo do não-observável, tocando numa alternativa que não se pode resolver simplesmente no âmbito das ciências naturais, e, no fundo, nem mesmo no da filosofia. Em outros termos, as ciências pretendem compor um discurso "científico" sobre algo que, segundo os próprios critérios das ciências, escapa ao domínio do controle científico-técnico, pois que não é objeto de verificação empírica (como é o caso do "fundamento" do dinamismo da vida). No limite, trata-se de saber se há algo racional no princípio de todas as coisas e no seu fundamento: o real nasceu por acaso ou por necessidade? Se por acaso, a razão seria um produto casual marginal do irracional, e, portanto, algo insignificante no oceano do irracional; se por necessidade, continuaria válida aquela que é a convicção fundamental do cristianismo: "no princípio era o Logos", a força criadora de algo como uma razão.

Evidentemente, Bento XVI não poderia defender que a razão se submeta à fé, dizendo simplesmente que esta pode oferecer uma resposta sobre o fundamento das coisas, pois isso significaria um atentado à autonomia da razão. Mas pode sustentar que a própria razão entre no domínio da fé, pois, diante de um impasse (como o de a razão pretender dar uma resposta técnica para uma questão que transcende os limites da técnica), a fé pode ser razoável aos olhos da mesma razão. Mas, mais do que isso, a própria razão pode interessar-se pelo problema do fundamento das coisas e encontrar, já em si mesma, a abertura para sua transcendência.

Para falar do impasse acima mencionado, Bento XVI recorre à gratuidade (no sentido de falta de justificativa ou mesmo de ausência de crítica) com que a razão, no mundo contemporâneo, renuncia àquela prioridade do racional sobre o irracional, ou ao Logos, como princípio primeiro, em favor do nada. Isso porque boa parte das racionalidades contemporâneas prefere dizer que, dada a explicação empírica, todo o restante de questões é irracional. Do ponto de vista da própria razão, essa renúncia é quase sempre infundada, porque os modelos hermenêuticos que se criam demonstram, como se disse acima, que a razão não pode pensar o irracional senão à sua medida, ou seja, racionalmente (haja vista a linguagem da resolução de problemas, da elaboração de métodos etc.), o que, no limite, termina por defender o primado contestado da razão. Se é assim, porque a razão não pode continuar sua pesquisa para além dos seus pretensos limites científico-técnicos, ou mesmo filosóficos? Não haverá mais nada de racional lá onde algumas das racionalidades contemporâneas dizem não ser mais o território da razão?

Diante desse impasse, o cristianismo não poderia aceitar a razoabilidade do refúgio no irracional, ao menos com os argumentos oferecidos até hoje 
pela história do pensamento, preferindo continuar com sua opção em favor do primado da razão, o que faria dela, ainda hoje, "racionalidade", pois que comporta uma resposta de sentido às perguntas que transcendem o âmbito da pesquisa científica e não se deixam calar no coração de todos os humanos. Refutando céticos como Richard Rorty, por exemplo, a experiência do pensamento, para o cristianismo, implicaria um discurso sobre a verdade, porque esta se mostra ao menos na forma da certeza da própria experiência do pensamento. Não se trata de ter a coragem de abrir mão de um absoluto, porque a sombra do absoluto sempre rondará a atividade humana de conhecimento (seja na forma da dúvida, do método, do perspectivismo, do inconsciente, do Estado etc.); trata-se, sim, de ter a coragem de assumir que talvez haja um princípio primeiro, na tentativa de inteligi-lo. Dessa perspectiva, o ethos da cientificidade seria dado por uma vontade indeclinável de obediência à verdade, o que coincide com uma das decisões essenciais do espírito cristão. ${ }^{7}$

Assim, com sua opção em favor do primado da razão ("No princípio era o Logos"), o cristianismo permaneceria hoje como o testemunho da necessidade de um alargamento do nosso conceito de razão e de seu uso, não se reduzindo aos limites que ela se autodecretou, mas assumindo a necessidade de transcendê-los, sob o risco de, não o fazendo, também não ser capaz de abordar o fenômeno humano no conjunto da sua complexidade. Essa necessidade nasceria do próprio exercício da razão; portanto, de sua autonomia, e não de uma inspiração externa. Assim, se há uma crítica de Bento XVI à modernidade, essa crítica não se refere ao livre uso da razão ou a algo como o Sapere aude! kantiano. Ao contrário, é defendendo uma fidelidade extrema à razão e ao seu primado que Bento XVI chama a modernidade a um reajuste. Mas isso não é ser fiel à modernidade iluminista? Nesse contexto, a questão de Deus não seria algo pertencente a uma subcultura; ao contrário, diante do fracasso da política, da economia e das artes como meio de obtenção da felicidade, essa questão se ergue, no cenário contemporâneo, como possibilidade de realização humana plena. Tomar isso a sério, tal como fizeram, por exemplo, já os judeus da Septuaginta, em sua simbiose com a cultura grega, seria, nas palavras de Bento XVI, uma forma autêntica de Aufklärung. Não reconhecê-lo seria correr o risco de se elaborar um pensamento profundamente reacionário, de volta ao passado pré-crítico, ao passo que, ao contrário, aceitando a estrutura racional da matéria e a correspondência entre o nosso espírito e as estruturas racionais operativas na natureza como um dado de fato, sobre o qual se baseia o seu percurso metódico, a razão pode, sim, aceitar que também se pergunte sobre o porquê de este dado de fato existir, confiando a busca de resposta a outros níveis e outros modos do pensar - não às ciências naturais, mas à filosofia e à teologia. Para a filosofia e, de

${ }^{7}$ Cf. "Fé, razão e universidade: recordações e reflexões", op. cit., p. 7. 
maneira diferente, para a teologia, a escuta das grandes experiências e convicções das tradições religiosas da humanidade pode constituir uma fonte de conhecimento; recusá-la significaria, nas palavras de Bento XVI, uma inaceitável redução da nossa capacidade de escutar e responder.

\section{A tradição cristã em contraponto com o Iluminismo segundo Bento XVI}

É justamente a ênfase de Bento XVI na capacidade humana de escutar e responder que nos permite tratar do modo como ele mesmo aborda a tradição cristã em contraponto com o Iluminismo.

Antes de tudo, é preciso dizer que o reconhecimento e a valorização dados pelo próprio Bento XVI ao Iluminismo, tal como vimos acima, é uma prova de que, para ele, a herança iluminista não pode ser desprezada. Aliás, em seu texto Verdade, tolerância, liberdade, ele diz explicitamente que não devemos esvaziar a herança do Iluminismo. Ele assim se pronuncia ao evocar a imagem que o filósofo polonês Andrzei Szczypiorski empregava para ilustrar as ilusões que também nasceram do Iluminismo, sobretudo aquelas ligadas à ideia de progresso da humanidade. Szczypiorski fazia um diagnóstico pessimista, dizendo que, depois de dois séculos de funcionamento útil e sem problemas, a máquina a vapor do Iluminismo parou sob o nosso nariz; o vapor só faz espalhar-se no ar. Bento XVI, em resposta, diz, em primeiro lugar, que é preciso lembrar que o trabalho dessa máquina não se realizou sem problemas; bastaria lembrarmo-nos das duas guerras mundiais e das ditaduras do último século. Entretanto, diz ele:

(...) eu gostaria de acrescentar que não precisamos de modo algum esvaziar a herança do Iluminismo como tal e em bloco para explicar o emperramento da máquina a vapor. O que precisamos é corrigir o seu curso (...). ${ }^{8}$

Como vemos, Bento XVI não trata do Iluminismo em bloco e defende mesmo a legitimidade de sua herança.

Falando de modo geral a respeito da razão, Bento XVI opera um contraponto entre as tradições religiosas e ela. No texto $A$ fé entre razão e sentimento, inserido por ele no capítulo Verdade do cristianismo da obra Fé, verdade e tolerância, ele chega a falar não somente de uma patologia da razão, mas também de uma patologia da religião. A patologia da razão seria um fechamento da razão em si mesma, produzindo uma ciência perigosa para a vida na medida em que ela se dessolidariza da concepção de conjunto da ordem habitual do ser humano e se reconhece como única medida de suas próprias

${ }^{8}$ RATZINGER, J. “Vérité, tolérance, liberté". In: 273. Foi, vérité, tolérance, op. cit., p. 
possibilidades. Na contrapartida, a patologia da religião também seria um fechamento da religião em si mesma, sem diálogo com a razão, sem interrogar-se razoavelmente sobre as coisas essenciais da vida, sua origem e seu fim, sobre o que se pode e o que se deve, deixando um sentimento separado da razão dominar essas questões. Diz ele explicitamente:

A desintegração do homem que segue daí conduz do mesmo modo à patologia da religião e à patologia da ciência. Há, hoje em dia, em número crescente, formas patológicas da religião, nas quais a religião se recusa a assumir sua responsabilidade diante da razão. ${ }^{9}$

Certamente o contraponto que Bento XVI fizera entre o Iluminismo e a tradição cristã, tal como vimos acima, contribui para a compreensão do sentido que ele atribui à razão. Agora, denunciando as patologias da religião, ele defende que esta não se desvincule do trabalho racional e de suas exigências.

Refletindo especificamente sobre a tradição cristã, Bento XVI vai ainda além e a contrapõe diretamente ao Iluminismo, expressão mais aguda da autonomia da razão. Em sua obra Os princípios da teologia católica Esquema e materiais, o então cardeal Ratzinger afirma que a fé cristã é aberta à cultura esclarecida e, na busca do encontro com ela, percorre uma parte de seu caminho em comum com o Iluminismo.

O contexto em que ele faz esse contraponto da fé cristã com o Iluminismo é dado pela análise de um paradoxo: de um lado, o cristianismo insiste na simplicidade da fé; de outro, não se pode negar o caráter racional da fé.

Com efeito, identificar-se-ia, na Igreja, uma nostalgia do passado, que associaria a fé com a simplicidade e a não necessidade da atividade racional. ${ }^{10}$ Entre vários exemplos, Bento XVI menciona a Imitação de Cristo, que, na aurora dos tempos modernos, protestava contra o empobrecimento da fé na forma de uma teologia que se tornava pura erudição. Seu autor tomava a opção decidida pelo cristianismo dos simples. Indo um pouco para trás no tempo, encontra-se o exemplo de São Francisco de Assis, que se autodenominava com insistência "simples e ignorante; sem conhecimento e ignorante". Mas as raízes de tal atitude podem ser encontradas já nos Evangelhos, como, por exemplo, no elogio dos simples feito por Jesus: "Eu te louvo, Pai, Senhor do céu e da terra, pois escondeste essas coisas aos sábios e aos entendidos e as revelaste aos pequenos" (Mt 11, 25). Por outro lado, como diz Bento XVI, quem considera a profunda reflexão teológica das cartas paulinas e do Evangelho de João não pode escapar à convicção de que há, aí, algo mais. Instala-se, então, o paradoxo: como conciliar, em

\footnotetext{
${ }^{9}$ RATZINGER, J. "La foi entre raison et sentiment". In: cit., p. 166.

${ }^{10}$ Cf. RATZINGER, J. Les principes de la théologie catholique, op. cit., p. 375ss.
} 
Paulo, por exemplo, o desprezo pela sabedoria dos gregos e seu próprio combate referente ao conteúdo da fé, esforço esse que seria impensável sem a herança das sabedorias hebraica e grega? Como essas duas realidades caminham juntas na história da fé: a referência constante aos simples e o desenvolvimento sempre crescente do conhecimento teológico?

Como vemos, Bento XVI vai à raiz da relação entre a tradição cristã e a postura intelectual-racional. Quer dizer, ele localiza na própria fonte da fé, como são os documentos bíblicos, a necessidade de uma vinculação entre o ato de fé, com seus conteúdos afetivos, e a atividade racional, com suas exigências de coerência lógica, não absurdidade, diálogo com as elaborações conceituais do contexto histórico em que ela se insere etc. Muito antes do Iluminismo dos séculos XVII-XVIII, esse encontro deu-se já na era apostólica. E mesmo antes, pois, como lembra Bento XVI, Israel representou um papel iluminador diante do mundo antigo, instalado comodamente em suas religiões míticas. Os profetas criticam os deuses, as sacralidades dos povos e denunciam as hipocrisias. Israel pretende, numa palavra, destruir representações que não são conformes à verdade e que, por conseguinte, frustram o homem e tolhem sua liberdade. A fé no Deus criador único, que fez o mundo por sua palavra, não pode suportar a piedosa aparência dos mitos. E Bento XVI chama a essa atitude de Iluminismo (Aufklärung), ${ }^{11}$ dizendo que ela reconhece o direito reivindicado pela razão de não admitir outros limites senão aqueles de sua origem na vontade e na palavra criadora de Deus.

Igualmente, a fé cristã, desde suas origens, sente-se chamada a ir ao encontro dos homens. Ela é destinada a todos, porque "Deus quer que todos os homens sejam salvos e cheguem ao conhecimento da verdade" $(1 \mathrm{Tm} 2,4)$. A fé, portanto, implica a orientação para os outros, e, indo ao encontro do outro, eu me questiono necessariamente a mim mesmo. Transformando a palavra em resposta, eu me instruo na fé de modo mais profundo e novo. Essa caridade implicada na fé aponta também para o seu caráter racional: a caridade que vem da fé deve ser uma caridade compreensiva, que não dá somente pão ao próximo, mas que lhe ensina a ver. A fé, portanto, mostra-se não como um ato cego, uma confiança sem conteúdo, mas como uma abertura dos olhos, abertura do homem à verdade. Dessa perspectiva, a fé cristã é mais otimista e mais radical do que o mundo cultural, não apenas da Antiguidade, mas também dos tempos modernos, porque na Modernidade a questão da verdade é considerada como algo de quase indecente, estranho à ciência e à cultura (pode-se considerar o caráter "correto", "coerente" dos sistemas, mas a verdade permanece escondida).

Em seu serviço missionário, a fé cristã viveu um verdadeiro drama em suas origens, afinal, por seu conteúdo, ela foi considerada como um ataque contra o mundo da religião em geral do mundo antigo, uma aliada do

${ }^{11}$ Cf. idem, p. 380. 
"Iluminismo" (Aufklärung) que destruía, ao mesmo tempo, a religião e os fundamentos do mundo. É por isso que os cristãos eram acusados e condenados por "ateísmo". De fato, os progressos da razão haviam, já fazia bastante tempo, desvalorizado e arruinado os fundamentos religiosos antigos. A desagregação espiritual estava em curso e somente uma religião nova, resistente perante esses progressos da razão, podia oferecer um rearranjo da prática religiosa. Essa religião foi o cristianismo, aquela que tomou forma no encontro com Deus em Jesus Cristo e que sobreviveu ao mundo antigo. Como diz Bento XVI,

O que caracteriza, então, a fé cristã entre todas as religiões é que ela põe o homem no caminho da verdade, ela lhe dá um apoio não em seus costumes, mas na verdade, e que ela reivindica assim, para ela mesma, o apanágio da razão. Ela é infiel a si mesma se ela se esconde diante da razão. Combater a ignorância e afastar a hipocrisia fazem parte de suas tarefas. A busca da cultura lhe é imposta a partir de dentro. ${ }^{12}$

Evidentemente, Bento XVI não pretende dizer que só pode ser um cristão adulto aquele que desenvolver sua razão teórica. Ao contrário, o cristianismo sempre defendeu a dignidade de todos os seres humanos, de modo que um homem simples, dotado do senso dos valores supremos, pode ser infinitamente mais cultivado do que um tecnocrata experimentado. Mas isso não impede de afirmar a vocação iluminista da fé cristã.

Disso tudo podemos depreender que, diante do Iluminismo histórico, aquele característico da Modernidade, o cristianismo é chamado, antes de tudo, a dialogar e a levar adiante sua missão de eruditio, ${ }^{13}$ de refinamento do homem em sua vocação à abertura e à profundidade.

Desse ponto de vista, não amedronta o lema Iluminista, cristalizado pelo texto kantiano com seu Sapere aude! A liberdade do exercício racional do indivíduo é um dom inegociável e é a partir dela que o indivíduo deve entrar no mundo da fé. Aliás, o próprio Kant distinguia entre um uso público e um uso privado da razão. O uso público seria aquele que qualquer homem, enquanto sábio, faz da razão diante do grande público do mundo letrado. $\mathrm{O}$ uso privado seria aquele que o sábio pode fazer de sua razão em um cargo público ou função a ele confiado. ${ }^{14}$ Assim, no uso privado, ocupando uma função ou cargo, o sábio deve obedecer, mas, justamente enquanto sábio, não age contrariamente ao dever de cidadão se expõe publicamente suas ideias contra a inconveniência ou a injustiça de imposições feitas a esse cargo.

Esse uso da liberdade individual, exercida na comunidade com os semelhantes, certamente vai ao encontro da posição de Bento XVI. A questão

\footnotetext{
${ }^{12}$ Idem, p. 381.

${ }^{13}$ Cf. idem, p. 383.

${ }^{14}$ Cf. KANT, I. "Resposta à pergunta...", op. cit., p. 66.
} 
que Bento XVI levanta, no entanto, é a de saber como unir justiça e liberdade. Diz ele:

A liberdade do homem é uma liberdade partilhada, uma liberdade no sercom de outras liberdades que se limitam mutuamente, apoiando-se assim mutuamente. Ela deve medir-se pelo que sou, pelo que somos; do contrário, ela se suprime a si mesma. Chegamos assim a uma correção de sua imagem superficial, aquela que domina hoje: se a liberdade humana não pode consistir senão num ordenamento de um ser-com de liberdades, isso quer dizer que essa ordem, o justo, não é sua antítese, mas sua condição, um de seus elementos constitutivos: a ausência do justo é a ausência de liberdade. Com certeza, saber isso levanta outra questão: qual é o justo conforme à liberdade? Como estabelecer o direito para que ele seja o direito da liberdade? Pois existem seguramente direitos aparentes que são direitos de escravos; eles não dizem o que é justo, mas são uma forma regularizada de injustiça. ${ }^{15}$

Encontrar esse justo é, sem dúvida, a maior questão da história da liberdade. E a principal vocação do cristianismo, que pretende iluminar a cultura. Numa palavra, podemos dizer que é conatural ao cristianismo ir ao encontro da cultura, para compreendê-la e dialogar com ela. Não, porém, como se o cristianismo deixasse a cultura falar, para, no fim das contas, ele a condenar e impor-lhe a sua verdade. Trata-se, antes de tudo, da vocação do cristianismo para a tentativa de compreender a cultura, com suas razões e seus anseios, a fim de que aquilo que ela apresenta leve o próprio cristianismo a um melhor autoconhecimento e à possibilidade de ajustar seu anúncio à busca do homem letrado, iluminando-lhe a existência. Os textos de Bento XVI revelam essa preocupação, e, num tom explícito de serviço à inteligência humana, ele não manifesta nenhum medo nem nenhuma arrogância, mas a caridade de ir ao encontro do homem, mantendo-se fiel à natureza cristã de buscar a luz e de oferecê-la a todos.

Endereço ao Autor:

Rua Guiará, 213 - Pompeia

05025-020 - São Paulo (SP)

jsfilho@usp.br

${ }^{15}$ RATZINGER, J. "Liberté-vérité". In: Foi, vérité, tolérance, op. cit., p. 265-266. 